\title{
Innovations
}

\section{Academic departmental meetings via video link: the Welsh experience}

\author{
Paul Mallett, Lecturer, and Peter McGuffin, Professor, Department of \\ Psychological Medicine, University of Wales College of Medicine, Cardiff CF4 4XN
}

The problem of geographical dispersion is common in clinical academic departments. Often there is a main departmental base in a teaching hospital with various smaller units either elsewhere on the same campus or based in other hospitals in the same city. In addition, staff may do their ward work, out-patient clinics and their associated clinical teaching scattered over a number of sites. Although these arrangements usually have some effects on departmental cohesion, problems can usually be overcome with a little effort and the traditional means of ensuring communication and developing common policies in teaching, research and service development has been to hold regular departmental meetings.

The main threat to the effectiveness of departmental meetings in recent years has been the tendency in a number of medical schools to set up clinical academic posts or whole units outside the main teaching districts and often a considerable distance from the parent department. The impetus has usually been a desire to enhance postgraduate training in non teaching districts, but in practice the more peripherally based clinical academics can also become vital contributors to their department's research and medical undergraduate training activities so that maintaining good communication is essential. Inevitably the problems are greater where distances are large and the area whose postgraduate needs are served by the medical school is not so much a 'patch' as an expansive tract of territory. This is well exemplified by Wales, a country with a population of nearly three million but only one medical school, the University of Wales College of Medicine (UWCM) based in Cardiff.

In 1989 UWCM set up an Academic Subdepartment of Psychological Medicine at the North Wales Hospital in Denbigh with the active support of

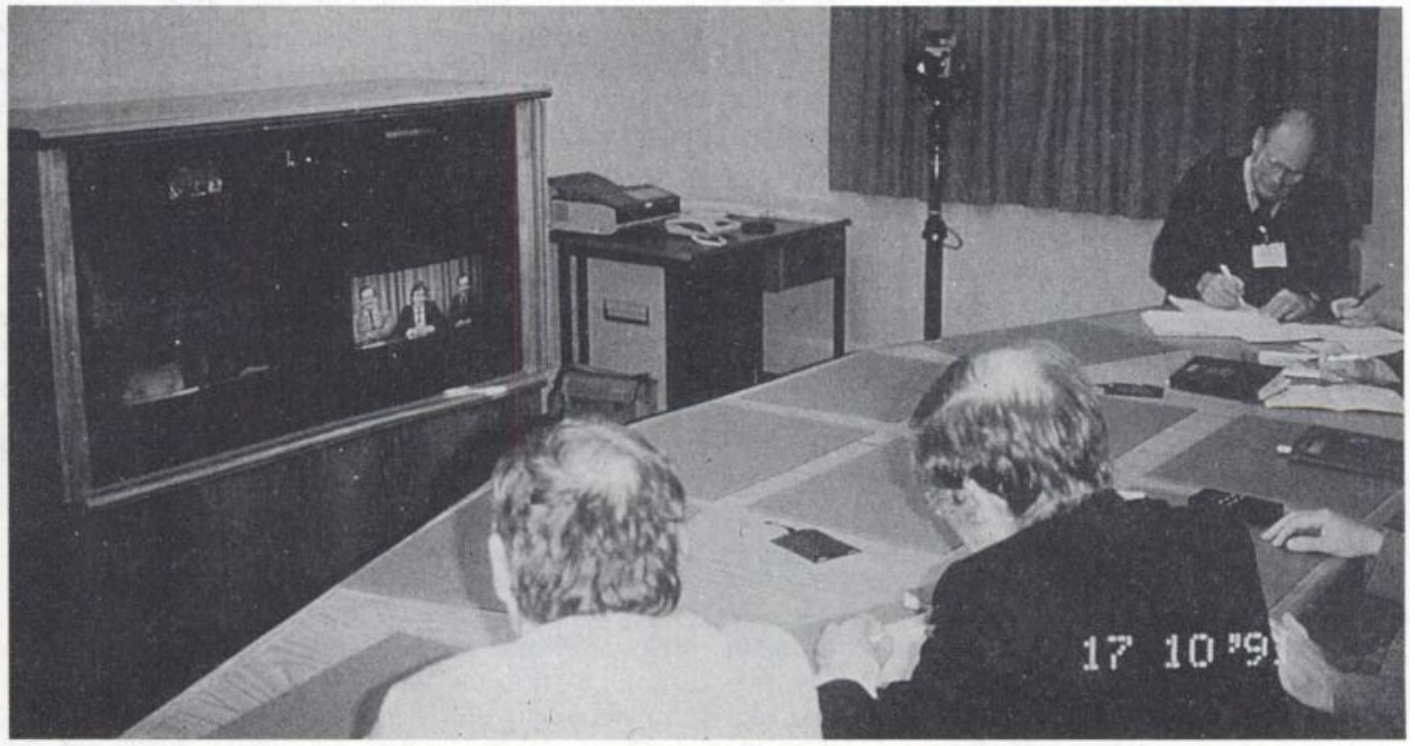

A televideo department meeting. 
the two North Wales Health Authorities, Clwyd and Gwynedd, and the Welsh Office. The Sub-department enjoys excellent facilities in an idyllic semi-rural setting and was officially opened by the President of the College, Professor Andrew Sims, in 1990 (Psychiatric Bulletin, 1991, 15, 31-32). However, it suffers from one major disadvantage: it is 150 miles by road from the parent department. Most of the population of Wales, about two-thirds, is located in the South, principally in Cardiff, Swansea, Newport and other large towns. Most of the rest of the population are in the North in the Clwyd/English border areas and in the coastal Clwyd/Gwynedd coastal strip. In between these two concentrations of population North and South lies some of the most spectacularly beautiful countryside in Europe but it is mostly hilly, sometimes mountainous and occasionally wild. In the absence of Swiss-style motorways through the mountains, driving from North to South can be arduous and is rarely accomplished in less than four hours. Even some of the most fervently patriotic Welshmen will sometimes resort to a diversion via England when journeying from Cardiff to towns in North Wales!

\section{The solution}

It was clear from the beginning of the North Wales academic development that meetings with all members of the Department physically in the same room would have to be a rare event. Telephone conferencing was considered as one possible solution but this could never involve more than a small subset of the 30 academic and research staff in the South and the nine in the North. We therefore decided to experiment with video conferencing. A video link using telephone lines had already been set up by the Welsh Joint Health Services Authority to facilitate communication between health districts. In Cardiff there is a televideo studio at Whitchurch which can communicate with an exactly similar studio in Mold, Clwyd. The layout of the studios are represented diagrammatically in the Figure. Essentially the studio looks something like a board room with one side of the table occupied by a row of chairs in the conventional fashion but with the other side taken up by large television screens. A second row of chairs can be installed on the seating side so that up to 20 people (and more at a squeeze) can be seen on camera.

As we can see from the diagram, there are facilities for visual presentation of material via a separate camera system with a remote control facility. In addition, a fax connection allows for rapid transfer of letters, minutes, and other documents. The cameras can all be flexibly used to focus on one particular speaker or to encompass a wider angle. Using the wider angle shots and a little effort in the suspension of

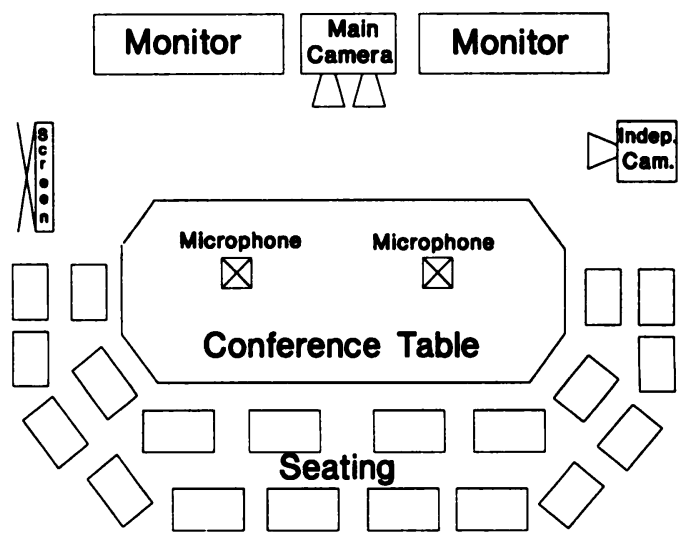

Fig. Layout of televideo studio.

disbelief, it is possible to hold conversations between the two sides of the table as if everybody were in the same room.

\section{The drawbacks}

On entering the studios some departmental members inevitably feel inhibited by the technology and at the presence of cameras and microphones. However, any feelings of camera shyness or unease about the artificial nature of the process are rapidly overcome and the discussion proceeds as it would in almost any other meeting.

The more obvious disadvantage is cost. The department is fortunate in having access to health authority facilities which were set up precisely with the aim that an initial outlay would soon be recouped in savings in time and travel expenses. For the same reason similar televideo link-ups are being set up within the University of Wales for communication between constituent colleges. Both the health authority and the university have to use telephone links for their televideo systems in order to reduce the costs. This creates another slight problem of a technical nature. In order to use telephone links the video image has to be digitalised before it can be transmitted. Consequently there is a very short but perceptible delay in two way conversations between the studios.

\section{Future applications}

Despite these minor drawbacks the video links between North and South Wales have been a boon to the Department of Psychological Medicine and have proved a very effective way of overcoming distance without the time and expense of physical travel. We intend to go on with televideo departmental meetings 
and reduce the number of conventional meetings involving all academic and research staff to once a year. The potential for other developments, especially for distance learning and MRCPsych courses, is obviously considerable and exploration of the scope of educational uses of televideo links is an important item for future agendas. As we remarked earlier, we are aware of other departments that have similar problems of geographical explosion even if not quite as marked as our own. We would recommend to them that the televideo conference solution is well worth exploring.

\title{
The times
}

\section{Invalid Care Allowance - an allowance for the carers}

\author{
Philip Steadman, Registrar in Psychiatry, St George's Training Rotation, \\ London SW17
}

This is the third and last in my series on recent changes incorporating the introduction of Disability Living Allowance in the allowances for the mentally ill. The Invalid Care Allowance is unusual in that it is paid to the person who does the caring and not the person being cared for.

Like many other allowances, uptake is poor due to carers not knowing about it. Psychiatrists can do a lot to change this.

\section{Who qualifies}

Invalid Care Allowance is a Social Security benefit to help people who look after someone who gets Attendance Allowance (AA), Constant Attendance Allowance (CAA) or Disability Living Allowance (DLA) at the middle or higher rate for help with personal care.

From 6 April 1992, it is $£ 32.55$ per week; a Christmas bonus is also paid each year.

The following four points have to be met.

(a) A carer must be at least 16 but under 60 if a woman, 65 if a man.

(b) A carer must be looking after someone for at least 35 hours per week.

(c) The person cared for must be getting $\mathrm{AA}$, CAA or DLA as above.

(d) The carer must normally live in the U.K.

\section{Who doesn't qualify}

(a) As a carer on a course of full-time education (this is defined as 21 hours or more of fulltime study each week).

(b) A carer on holiday from a course of full-time education.

(c) A carer who earns $\mathbf{1 4 0}$ a week or more once expenses are taken off. Expenses allowance are things like child minding fees, fares to work and National Insurance contributions.

(d) If the person cared for has not applied for AA, CAA or DLA they should be encouraged to do so. The person cared for must know they are to receive one of those benefits before a claim can be made by the carer for invalid care allowance.

Carers who are getting Income Support, Housing Benefit or Community Charge support

If carers or their partners are getting Income Support, they should still claim for Invalid Care Allowance. The amount of invalid care paid is taken off the Income Support. However, after that, an extra amount of money called "Carer Premium" is added on to the Income Support. 